\title{
Original article (short paper) \\ Technical-tactical performance profile of the block and dig according to competition category in men's volleyball
}

\author{
Antonio García-de-Alcaraz \\ Faculty of Physical Activity and Sport Sciences, Polytechnic University of Madrid, Spain \\ Enrique Ortega \\ Faculty of Sport Sciences, University of Murcia, Spain
}

José M. Palao

University of Wisconsin-Parkside, United States

\begin{abstract}
The aim of this study was to analyse the technical-tactical performance profile of blocking and court defence actions for various age groups and categories of competition in men's volleyball. The sample comprised 16,454 blocks and 8,321 digs performed in 299 sets in several categories of competition (from U-14 to Olympic Games). A descriptive and correlational inter- and intra-group observational design was used. The variables studied were: category of competition, opponent's spike tempo, and block and dig performance. The results showed a significant increase in the percentage of blocks and digs derived from fast attacks and a significant improvement in performance of these actions to counteract slow attacks. Thus, improving in blocking and digging performance was observed at higher categories when the attack is performed slowly. This paper discusses various reasons for the evolution in defensive performance and the effects on the training process for various categories of competition in volleyball.
\end{abstract}

Keywords: team sports, performance, match analysis, volleyball

\section{Introduction}

In a volleyball play, the defending team tries to neutralise or restrain the opponent's offense through defensive actions such as blocking and court defence. The block is a team's first line of defence, and it aims to intercept, stop, or restrain the opponent's offensive actions (Selinger \& Ackermann-Blount, 1985). The main objective of court defence is to control the ball that was attacked by the opponent to send it to the setter and, thus, counterattack (Stone, 2002). Block and court defence performance depend on how an opponent's spike (e.g. attack tempo, distance from the ball, previous displacements) is performed (Selinger \& Ackermann-Blount, 1985) as well as on variables that determine the opponent's offense (e.g. setter's zone, available hitters, attack area) (Afonso \& Mesquita, 2011). The interaction of various game actions determines the performance of defensive actions such that performance may vary according to the age group and/or competition level. These changes are determined by players' maturity (e.g. greater height, weight, reach) (Malina \& Bouchard, 1991), progress in the training process (e.g. higher speed, better technical execution), and changes in game regulations (e.g. net height, libero), which may occur as players progress from one category to the next.

Block performance is associated with players' anthropometric features (e.g. height, weight, etc.), and behavioural and psychological abilities (e.g. reaction time) (Stamm, Stamm, $\&$ Thomson, 2005). One reason for this association is the fact that the height reached over the net is crucial (Grgantov, Katic, \& Jankovic, 2006; Stanganelli, Dourado, Oncken, Mancan, \& Costa, 2008), as it enables an appropriate technical-tactical execution. On the other hand, court defence performance requires the development of physiological factors (e.g. strength, flexibility, etc.), technical-tactical factors (hand-eye coordination, etc.), and psychological factors (optimal activation for a quick reaction to the opponent's attack) (Stone, 2002). Most of these performance factors are limited when the opponent's spike is carried out quickly. These quick attacks force defenders to react and move in the shortest possible time. Thus, quick attacks have greater efficiency (Bergeles \& Nikolaidou, 2011; Castro, Souza, \& Mesquita, 2011; Costa et al., 2011; Palao, Santos, \& Ureña, 2007) on account of the conditions in which the block is performed (Afonso, Mesquita, Marcelino, \& Silva, 2010) and limited defensive movements.

Despite the relationship between the spike and defensive actions, there is a lack of reference values in the scientific literature pertaining to technical-tactical performance of the block and court defences that take into consideration the opponent's spike tempo according to the various categories of competition. Reference values may be helpful in guiding training process and improving the performance of these actions. This study is the first step in establishing a technical-tactical performance profile of blocking and court defence. The aim was to assess technical-tactical performance profiles of blocking and court defence for various categories of competition in men's volleyball. 


\section{Method}

\section{Population and sample}

The sample was made up of teams and players participating in matches and sets in Spain's U-14, U-16, and U-19 men's championships (2008-2009 season), Spain's first division (national senior category, 2008-2009 and 2009-2010 seasons), and the 2008 Olympic Games (international senior category). The analysed actions comprised 16,454 blocks and 8,321 digs. These actions were played by 99 teams in 299 sets. Fifty-nine sets were randomly selected from the Olympic Games, while sixty sets were randomly selected from the other categories. The sets were stratified in terms of "performance level" (one of three rankings) and "quality of opposition" (six different options according to rival's level of performance). Given the different structure of the fifth set (FIVB, 2008), it was not included in the sample.

All matches were video recorded after the organizing committee had given consent. In the case of the Olympics, matches were not filmed, but downloaded from open online channels such as NBC. The process did not affect players' and teams' spontaneous behaviour, as filming is a common, non-invasive procedure typically used by coaches. This study complied with the Bioethics Commission of the University of Murcia (Spain) and with the ethical principles stated by the Declaration of Helsinki.

\section{Design}

A descriptive, correlational, observational (nomothetic, intra sessional, and multidimensional) design were implemented through of a category system (Anguera, 2003). The study's variables were: a) category of competition (U-14, U-16, U-19, national senior, and international senior); b) attack tempo (first, second, or third tempo); and c) the performance of the block and dig. A first, second, or third tempo block or dig was an action or attempted action responding to a first, second, or third tempo spike, respectively. Block and dig performance were measured in terms of the defending team's ability to counterattack under the best possible conditions. The performance of the block was measured in terms of the opponent's ability to continue the play when the ball is returned to their court or in terms of the defending team's ability to continue the play when the ball remains in their court (Table 1). Performance of the dig was measured in terms of the defending team's ability to continue the play (Table 2).

Table 1. Variables for block performance.

\begin{tabular}{ccl}
\hline Value & Category & Description \\
\hline 0 & Error & Block error. Point is lost after block contact \\
0 & Error (fault) & $\begin{array}{l}\text { Block error. Point is lost because blocker commits a fault (touching the net, penetration, etc.) } \\
\text { Block continuity. The blocking team cannot set up a counterattack, but when the ball is in the } \\
\text { opponent's court, the opposing team can counterattack }\end{array}$ \\
3 & Positive block & $\begin{array}{l}\text { Block continuity. The blocking team can set up a counterattack, and if the ball remains in the } \\
\text { opponent's court, the opponent cannot counterattack }\end{array}$ \\
& Point & Block point. The player who blocks sends it to the court on the other side of the net \\
\hline
\end{tabular}

Table 2. Variables for dig performance.

\begin{tabular}{ccl}
\hline Value & Category & Description \\
\hline 0 & $\begin{array}{c}\text { Error } \\
\text { Negative dig }\end{array}$ & $\begin{array}{l}\text { Dig error. Point is lost after dig contact } \\
\text { Dig continuity. The digging team continues the play but is not able to set up a counterattack, or the ball is sent } \\
\text { to the opponent's court after digging } \\
\text { Dig continuity. The digging team continues the play and maintains the possibility of setting up a counterat- } \\
\text { tack }\end{array}$ \\
\hline
\end{tabular}

\section{Procedure and instruments}

Competitions were recorded on video cameras placed at the end of the court and at a height higher than the net, except for the matches from the Olympic Games where filming took place from the sides and back of the court. It was ensured that the official court area $(18 \times 9 \mathrm{~m})$ would be recorded, at a minimum, to allow clear viewing of all actions. Regular video cameras positioned on tripods and plugged in with extension cords were used. For the national senior category, matches were also downloaded from an official website.
Technical-tactical actions were observed by a single observer, who was licensed in sport science, was a volleyball coach with the highest coach certification in Spain, and had over ten years of experience in volleyball training and performance analysis. To assess the adequacy of data coding and variables, a training process which included analysing twelve national senior-category matches was undertaken before starting the research study. The videos were observed in the month after the end of each tournament. The consistency analysis (Cronbach's Alpha) was conducted with two observers who were volleyball coaches with over two years of experience in performance 
analysis, and in the use of the observational software used in this study, and who held the highest national coach certification. For the inter-observer reliability analysis, $25 \%$ of sets from the national senior category were randomly selected and observed. Analyses showed a reliability of 0.865 for blocking and 0.820 for court defence. For intra-reliability analysis, 20\% of sets from each category of competition were randomly selected and observed. Analyses showed a reliability of 0.872 for blocking and 0.864 for court defence.

While observing, variables were recorded with the Data Volley software (Data Volley 2007, Data Project Sport Software, Bologna, Italy). Recorded actions were then synchronised with video images by means of Data Video (Data Video 2007, Data Project Sport Software, Bologna, Italy), so that the quality of the data could later be analysed. The data were collected and exported from Data Volley 2007 software using the observation tool's internal spreadsheets. Each spreadsheet contained players' and teams' performance during sets. All spreadsheets were merged into a single matrix in which contextual variables (category, team level, type of match, set result, game system, initial line-up, substitutions, and role of players) were added. SPSS 15.0.0 (Statistical Package for the Social Sciences, IBM, Armonk, United States) was used for descriptive and inferential analyses. The sample size was analysed in order to check the stability of data (Hughes \& Daniel, 2003). For all tested categories, stability occurred starting at the 17 th set, in the case of the block, and starting at the 10th set, in the case of court defence.

\section{Statistical analysis}

A descriptive analysis for the various actions and types of actions in every category of competition was performed. Frequency (number of actions or type of actions), relative frequency (relative measure for frequency), mean actions (team's mean value for the entire set), coefficient (mean value of performance of an action or type of action), efficacy (percentage of maximum performance of an action or type of action), efficiency (percentage of maximum value of an action when subtracting errors), and ratios (block point-to-error or positive-dig-to-negative-dig) were calculated. Coefficient, efficacy, efficiency and ratio were calculated using players' mean values per set. The following inferential tests were performed: a) KolmogorovSmirnov test to analyse normality of data; b) Kruskal-Wallis test $(p<0.05)$ to identify differences among categories; $\mathrm{c})$ Wilcoxon test $(p<0.05)$ to analyse differences within each category; and d) Mann Whitney U procedure with post hoc Bonferroni ( $p<$ 0.01 ) to analyse specific differences between categories.

\section{Results}

Results showed that at the initial stages (U-14, U-16, and U-19), the percentage of blocks with ball contact was significantly lower than the percentage of blocks with no ball contact (Table 3). These differences were not significant at later stages. At higher categories, the percentage of ball contacts increased significantly. Beginning with the U-14 category, the percentage of attack situations in which there were no block actions decreased significantly. The percentage of block attempts decreased significantly starting in the U-19 category. Regarding the tempo utilised to block, a predominance of third tempo blocks was observed in initiation stages (U-14, U-16 and U-19), and a predominance of second tempo blocks was observed in the senior stage. In higher categories; however, first and second tempo blocks increased significantly, while third tempo blocks decreased significantly. Starting at the U-16 category, all changes were significant, except for first and third tempo blocks, which changed significantly starting at the U-19 category.

Table 3. Number of blocks, mean team blocks per set, percentage of blocks per player per set, and statistically significant differences among categories.

\begin{tabular}{|c|c|c|c|c|c|c|c|c|c|c|c|c|c|c|c|}
\hline & \multicolumn{3}{|c|}{ U-14 } & \multicolumn{3}{|c|}{ U-16 } & \multicolumn{3}{|c|}{ U-19 } & \multicolumn{3}{|c|}{ National } & \multicolumn{3}{|c|}{ International } \\
\hline & $\mathrm{n}$ & Mean & $\%$ & $\mathrm{n}$ & Mean & $\%$ & n & Mean & $\%$ & n & Mean & $\%$ & $\mathrm{n}$ & Mean & $\%$ \\
\hline $\begin{array}{l}\text { Attempted } \\
\text { blocks }\end{array}$ & 1710 & 14.25 & $56.58^{\mathrm{A}}$ & 1887 & 15.73 & $54.31^{\mathrm{A}}$ & 1769 & 14.74 & $50.91^{\uparrow \mathrm{A}}$ & 1636 & 13.63 & $49.38^{\uparrow^{*}}$ & 1445 & 12.25 & $46.15^{\uparrow^{*} \downarrow}$ \\
\hline $1^{\text {st }}$ tempo & 37 & 0.31 & 2.22 & 98 & 0.82 & $5.26^{\uparrow}$ & 360 & 3.00 & $20.72^{\uparrow^{*}}$ & 397 & 3.31 & $24.20^{\uparrow^{*}}$ & 351 & 2.97 & $23.94^{\uparrow^{*}}$ \\
\hline $2^{\text {nd }}$ tempo & 0 & 0.00 & $0.00^{\mathrm{a}}$ & 56 & 0.47 & $2.80^{\uparrow a}$ & 125 & 1.04 & $7.33^{\uparrow a}$ & 771 & 6.43 & $47.57^{\uparrow * \downarrow a}$ & 834 & 7.07 & $58.02^{\uparrow^{*} \downarrow \downarrow \mathrm{a}}$ \\
\hline $3^{\text {rd }}$ tempo & 1673 & 13.94 & $97.78^{\mathrm{ab}}$ & 1733 & 14.44 & $91.94^{\uparrow a b}$ & 1284 & 10.70 & $71.95^{\uparrow^{* a b}}$ & 468 & 3.90 & $28.24^{\uparrow^{*} \downarrow b}$ & 260 & 2.20 & $18.03^{\uparrow^{*} \downarrow \backslash \mathrm{ab}}$ \\
\hline $\begin{array}{l}\text { Contacted } \\
\text { blocks }\end{array}$ & 642 & 5.35 & 20.70 & 1172 & 9.77 & $33.04^{\uparrow}$ & 1347 & 11.23 & $38.39^{{ }^{*}}$ & 1541 & 12.84 & $46.19^{\uparrow * \downarrow}$ & 1516 & 12.85 & $47.82^{\uparrow^{*} \downarrow}$ \\
\hline $1^{\text {st }}$ tempo & 37 & 0.31 & 6.63 & 76 & 0.63 & 6.34 & 231 & 1.93 & $17.82^{{ }^{*}}$ & 315 & 2.63 & $20.34^{\uparrow^{*}}$ & 242 & 2.05 & $16.28^{{ }^{*}}$ \\
\hline $2^{\text {nd }}$ tempo & 0 & 0.00 & $0.00^{\mathrm{a}}$ & 34 & 0.28 & $2.40^{\uparrow a}$ & 88 & 0.73 & $6.61^{\uparrow^{* a} \mathrm{a}}$ & 755 & 6.29 & $49.30^{\uparrow^{*} \downarrow \mathrm{a}}$ & 831 & 7.04 & $54.96^{\uparrow^{*} \downarrow \downarrow \mathrm{a}}$ \\
\hline $3^{\text {rd }}$ tempo & 605 & 5.04 & $93.37^{\mathrm{ab}}$ & 1062 & 8.85 & $91.27^{\mathrm{ab}}$ & 1028 & 8.57 & $75.57^{\uparrow * a b}$ & 471 & 3.93 & $30.36^{\uparrow^{*} \downarrow \mathrm{ab}}$ & 443 & 3.75 & $28.76^{\uparrow * \downarrow a b}$ \\
\hline No blocks & 660 & 5.50 & $22.72^{\mathrm{B}}$ & 443 & 3.69 & $12.65^{\uparrow \mathrm{AB}}$ & 350 & 2.92 & $10.19^{\uparrow^{*} \mathrm{AB}}$ & 149 & 1.24 & $4.43^{\uparrow^{*} \downarrow \mathrm{AB}}$ & 187 & 1.58 & $6.04^{\uparrow * \downarrow \backslash \mathrm{AB}}$ \\
\hline Total & 3012 & 25.10 & 100 & 3502 & 29.18 & 100 & 3466 & 28.88 & 100 & 3326 & 27.72 & 100 & 3148 & 26.68 & 100 \\
\hline
\end{tabular}


When analysing the performance of first tempo blocks (Table 4), a predominance of block points in the U-14 category and of block errors in the other categories were observed. Block errors increased significantly beginning in the U-19 category, while block errors due to faults decreased significantly starting at U-16. When analysing the performance of second tempo blocks (Table 4), a predominance of block errors in all categories was found, except for the U-14 category in which there were no such attacks. A statistically significant increase in positive blocks was detected when comparing senior categories (national and international) with U-19. As to the performance of third tempo blocks (Table 4), a predominance of block errors in all categories was observed. Regarding the national category, the evolution of performance of third tempo blocks showed a statistically significant decrease in errors due to faults and negative blocks. In contrast, a statistically significant increase in block points was found.

Table 4. Performance of contacted blocks with regard to spike tempo, and statistically significant differences between categories.

\begin{tabular}{|c|c|c|c|c|c|c|c|c|c|c|c|c|c|c|c|c|}
\hline & & \multicolumn{3}{|c|}{ U-14 } & \multicolumn{3}{|c|}{ U-16 } & \multicolumn{3}{|c|}{ U-19 } & \multicolumn{3}{|c|}{ National } & \multicolumn{3}{|c|}{ International } \\
\hline & & n & Mean & $\%$ & $\mathrm{n}$ & Mean & $\%$ & $\mathbf{n}$ & Mean & $\%$ & $\mathbf{n}$ & Mean & $\%$ & $\mathbf{n}$ & Mean & $\%$ \\
\hline \multirow{5}{*}{$\begin{array}{c}1^{\text {st }} \text { tempo } \\
\text { block }\end{array}$} & Error & 4 & 0.03 & 11.67 & 21 & 0.18 & 25.98 & 73 & 0.61 & $30.07^{\uparrow}$ & 113 & 0.94 & $37.02^{\uparrow}$ & 105 & 0.89 & $42.88^{\uparrow *}$ \\
\hline & $\begin{array}{l}\text { Error } \\
\text { (rule) }\end{array}$ & 6 & 0.05 & 16.67 & 1 & 0.01 & $1.09^{\uparrow a}$ & 10 & 0.08 & $3.82^{\mathrm{a}}$ & 8 & 0.07 & $2.08^{\mathrm{a}}$ & 4 & 0.03 & $2.18^{\uparrow a}$ \\
\hline & $\begin{array}{l}\text { Negative } \\
\text { block }\end{array}$ & 7 & 0.06 & 16.67 & 22 & 0.18 & $24.60^{\mathrm{b}}$ & 54 & 0.45 & $20.91^{b}$ & 77 & 0.64 & $21.90^{\mathrm{ab}}$ & 34 & 0.29 & $15.00^{\mathrm{ab}}$ \\
\hline & $\begin{array}{l}\text { Positive } \\
\text { block }\end{array}$ & 8 & 0.07 & 25.00 & 18 & 0.15 & $24.96^{\mathrm{b}}$ & 47 & 0.39 & $23.33^{b}$ & 63 & 0.53 & $20.25^{\mathrm{ab}}$ & 61 & 0.52 & $25.00^{\mathrm{abc}}$ \\
\hline & Point & 12 & 0.10 & 30.00 & 14 & 0.12 & $23.37^{\mathrm{b}}$ & 47 & 0.39 & $21.87^{\mathrm{b}}$ & 54 & 0.45 & $18.74^{\mathrm{ab}}$ & 38 & 0.32 & $14.94^{\mathrm{abd}}$ \\
\hline \multirow[t]{3}{*}{ Total } & & 37 & 0.31 & 100 & 76 & 0.63 & 100 & 231 & 1.93 & 100 & 315 & 2.63 & 100 & 242 & 2.05 & 100 \\
\hline & Error & 0 & 0.00 & - & 13 & 0.11 & 41.12 & 36 & 0.30 & 49.28 & 358 & 2.98 & 46.36 & 393 & 3.33 & 48.62 \\
\hline & $\begin{array}{l}\text { Error } \\
\text { (rule) }\end{array}$ & 0 & 0.00 & - & 0 & 0.00 & $0.00^{\mathrm{a}}$ & 2 & 0.02 & $1.90^{\mathrm{a}}$ & 16 & 0.13 & $2.36^{\mathrm{a}}$ & 13 & 0.11 & $1.83^{\mathrm{a}}$ \\
\hline \multirow[t]{3}{*}{$\begin{array}{c}2^{\text {nd }} \text { tempo } \\
\text { block }\end{array}$} & $\begin{array}{l}\text { Negative } \\
\text { block }\end{array}$ & 0 & 0.00 & - & 8 & 0.07 & $22.89^{\mathrm{b}}$ & 14 & 0.12 & $16.42^{\mathrm{ab}}$ & 118 & 0.98 & $16.92^{\mathrm{ab}}$ & 105 & 0.89 & $12.78^{\mathrm{ab}}$ \\
\hline & $\begin{array}{c}\text { Positive } \\
\text { block }\end{array}$ & 0 & 0.00 & - & 6 & 0.05 & $19.69^{b}$ & 15 & 0.13 & $11.33^{\mathrm{ab}}$ & 140 & 1.17 & $18.19^{\downarrow a b}$ & 162 & 1.37 & $18.78^{\downarrow \mathrm{abc}}$ \\
\hline & Point & 0 & 0.00 & - & 7 & 0.06 & $16.30^{\mathrm{b}}$ & 21 & 0.18 & $21.06^{\mathrm{ab}}$ & 123 & 1.03 & $16.17^{\mathrm{ab}}$ & 158 & 1.34 & $18.00^{\mathrm{abc}}$ \\
\hline \multirow[t]{3}{*}{ Total } & & 0 & 0.00 & - & 34 & 0.28 & 100 & 88 & 0.73 & 100 & 755 & 6.29 & 100 & 831 & 7.04 & 100 \\
\hline & Error & 225 & 1.88 & 38.01 & 359 & 2.99 & 33.90 & 359 & 2.99 & 36.70 & 157 & 1.31 & 33.87 & 140 & 1.19 & 32.10 \\
\hline & $\begin{array}{l}\text { Error } \\
\text { (rule) }\end{array}$ & 35 & 0.29 & $6.26^{\mathrm{a}}$ & 71 & 0.59 & $7.29^{\mathrm{a}}$ & 55 & 0.46 & $5.87^{\mathrm{a}}$ & 12 & 0.10 & $2.81^{\uparrow^{*} \downarrow \mathrm{a}}$ & 6 & 0.05 & $1.36^{\uparrow^{*} \downarrow a}$ \\
\hline \multirow[t]{3}{*}{$\begin{array}{c}3^{\text {rd }} \text { tempo } \\
\text { block }\end{array}$} & $\begin{array}{c}\text { Negative } \\
\text { block }\end{array}$ & 119 & 0.99 & $17.89^{\mathrm{ab}}$ & 211 & 1.76 & $18.44^{\mathrm{ab}}$ & 229 & 1.91 & $20.27^{\mathrm{ab}}$ & 83 & 0.69 & $17.14^{\mathrm{ab}}$ & 68 & 0.58 & $15.14^{*} \downarrow a b$ \\
\hline & $\begin{array}{l}\text { Positive } \\
\text { block }\end{array}$ & 123 & 1.03 & $21.49^{\mathrm{ab}}$ & 243 & 2.03 & $22.47^{\mathrm{abc}}$ & 235 & 1.96 & $22.49^{\mathrm{ab}}$ & 92 & 0.77 & $18.30^{\mathrm{ab}}$ & 117 & 0.99 & $25.24^{\mathrm{bc}}$ \\
\hline & Point & 103 & 0.86 & $16.35^{\mathrm{ab}}$ & 178 & 1.48 & $17.90^{\mathrm{abd}}$ & 150 & 1.25 & $14.68^{\mathrm{abcd}}$ & 127 & 1.06 & $27.88^{\left.\uparrow^{*}\right\lrcorner \mathrm{bcd}}$ & 112 & 0.95 & $26.15^{\mathrm{bcc}}$ \\
\hline Total & & 605 & 5.04 & 100 & 1062 & 8.85 & 100 & 1028 & 8.57 & 100 & 471 & 3.93 & 100 & 443 & 3.75 & 100 \\
\hline
\end{tabular}

Note. ${ }^{\uparrow} p<.01$ when compared to U-14. ${ }^{*} p<.01$ when compared to U-16. ${ }^{\downarrow} p<.01$ when compared to U-19. $p<.01$ when compared to national category. ${ }^{\text {a }}$

Significant differences when compared to "error". " Significant differences when compared to "rule error". "Significant differences when compared to "negative block". 'Significant differences when compared to "positive block".

As for statistical parameters of total blocks (Table 5), a statistically significant decrease in the block point-to-error ratio between U-14 and senior categories (national and international) and a statistically significant increase in this same variable between U-14 and U-19 were found. Also, a statistically significant increase in efficacy starting at the national senior category was found. When analysing statistical parameters of first and second tempo blocks, there was a significant increase in the block pointto-error ratio as of the national senior category. Furthermore, there was a significant increase in the percentage of errors in first tempo blocks between the U-16 and international senior categories. Regarding the third tempo block, an increase in the coefficient, efficacy, and efficiency beginning with the senior national category was observed, while a statistically significant decrease in percentage of error (between the initiation categories and the international senior category) and in the block point-toerror ratio (beginning with U-19) was also observed.

For court defence (Table 6), there was a significant predominance of digs with ball contact versus digs without ball contact throughout all categories. From the senior category upwards, a significant decrease in the percentage of digs with ball contact and a significant increase in the percentage of digs without ball contact were observed. For both types of dig, a predominance of third tempo actions at initial stages (U-14, U-16 and U-19) and of second tempo actions at senior stages (national and international) were found. A statistically 
significant increase in digs for first and second tempo attacks and a statistically significant decrease in digs for third tempo attacks were observed. These changes were significant beginning with U-16, except for first and third tempo digs with ball contact, which increased significantly from the U-19 category upwards.

Table 5. Block performance values and statistically significant differences between categories.

\begin{tabular}{|c|c|c|c|c|c|c|c|c|c|c|c|}
\hline \multirow{2}{*}{ Type of block } & \multirow{2}{*}{ Statistical data } & \multicolumn{2}{|l|}{ U-14 } & \multicolumn{2}{|l|}{ U-16 } & \multicolumn{2}{|l|}{ U-19 } & \multicolumn{2}{|l|}{ National } & \multicolumn{2}{|c|}{ International } \\
\hline & & Mean & SD & Mean & SD & Mean & SD & Mean & SD & Mean & SD \\
\hline \multirow{5}{*}{ Total Blocks } & Coefficient & 1.51 & 0.85 & 1.59 & 0.58 & 1.50 & 0.48 & 1.54 & 0.43 & 1.57 & 0.52 \\
\hline & Efficacy (\%) & 17.28 & 17.90 & 18.14 & 14.42 & 15.98 & 11.70 & $20.02 \downarrow$ & 11.39 & $19.72 \downarrow$ & 11.61 \\
\hline & Error $(\%)$ & 43.80 & 27.41 & 40.17 & 16.64 & 41.11 & 16.67 & 43.35 & 12.92 & 45.32 & 15.53 \\
\hline & Efficiency (\%) & -26.52 & 38.53 & -22.03 & 24.54 & -25.13 & 22.93 & -23.33 & 20.60 & -25.60 & 23.21 \\
\hline & Point:error & $1: 2.35$ & 1.78 & $1: 2.34$ & 1.79 & $1: 2.45 \uparrow$ & 2.01 & $1: 2.18 \uparrow$ & 1.90 & $1: 2.15 \uparrow$ & 1.82 \\
\hline \multirow{5}{*}{ 1st tempo block } & Coefficient & 2.12 & 1.60 & 1.93 & 1.46 & 1.78 & 1.24 & 1.58 & 1.15 & 1.50 & 1.16 \\
\hline & Efficacy (\%) & 30.00 & 44.72 & 23.37 & 40.28 & 21.87 & 31.24 & 18.74 & 28.19 & 14.94 & 26.41 \\
\hline & Error (\%) & 28.33 & 42.92 & 27.07 & 39.55 & 33.89 & 35.29 & 39.10 & 35.41 & $45.06^{*}$ & 37.27 \\
\hline & Efficiency (\%) & 1.67 & 73.68 & -3.70 & 65.67 & -12.02 & 56.09 & -20.36 & 53.55 & -30.13 & 52.75 \\
\hline & Point:error & $1: 0.83$ & 0.32 & $1: 1.57$ & 0.60 & $1: 1.77$ & 0.96 & $1: 2.24 \uparrow$ & 1.05 & $1: 2.87 \uparrow$ & 0.73 \\
\hline \multirow{5}{*}{ 2nd tempo block } & Coefficient & . & . & 1.47 & 1.13 & 1.35 & 1.38 & 1.36 & 0.69 & 1.41 & 0.73 \\
\hline & Efficacy (\%) & . & . & 16.30 & 19.84 & 21.06 & 31.54 & 16.17 & 15.20 & 18.00 & 16.97 \\
\hline & Error (\%) & . & . & 41.12 & 38.41 & 51.19 & 42.10 & 48.72 & 20.94 & 50.45 & 20.09 \\
\hline & Efficiency (\%) & . & . & -24.82 & 46.93 & -30.13 & 66.62 & -32.55 & 30.95 & -32.45 & 32.95 \\
\hline & Point:error & . & . & $1: 1.86$ & 0.66 & $1: 1.81$ & 0.68 & $1: 3.04 \downarrow$ & 1.70 & $1: 2.57 \downarrow$ & 1.64 \\
\hline \multirow{5}{*}{ 3rd tempo block } & Coefficient & 1.48 & 0.87 & 1.58 & 0.58 & 1.46 & 0.59 & $1.84 \uparrow * \downarrow$ & 0.94 & $1.95 \uparrow * \downarrow$ & 1.03 \\
\hline & Efficacy (\%) & 16.35 & 17.83 & 17.90 & 14.83 & 14.68 & 13.14 & $27.88 \uparrow * \downarrow$ & 24.66 & $26.15 \downarrow$ & 27.36 \\
\hline & Error (\%) & 44.27 & 28.34 & 41.19 & 17.80 & 42.57 & 20.71 & 36.68 & 26.05 & $33.46 \uparrow * \downarrow$ & 28.59 \\
\hline & Efficiency (\%) & -27.92 & 39.59 & -23.29 & 25.05 & -27.89 & 27.91 & $-8.80 \uparrow^{*} \downarrow$ & 44.13 & $-7.31 \uparrow * \downarrow$ & 47.64 \\
\hline & Point:error & $1: 2.52$ & 1.80 & $1: 2.42$ & 1.82 & $1: 2.76 \uparrow$ & 1.69 & $1: 1.33 \uparrow * \downarrow$ & 0.95 & $1: 1.30 \uparrow * \downarrow$ & 1.08 \\
\hline
\end{tabular}

Note. ${ }^{\uparrow} p<.01$ when compared to U-14. ${ }^{*} p<.01$ when compared to U-16. ${ }^{\downarrow} p<.01$ when compared to U-19. ${ }^{\natural} p<.01$ when compared to national category.

Table 6. Number of digs, mean team digs per set, percentage of digs per player per set, and statistically significant differences between categories.

\begin{tabular}{|c|c|c|c|c|c|c|c|c|c|c|c|c|c|c|c|}
\hline & \multicolumn{3}{|c|}{ U-14 } & \multicolumn{3}{|c|}{ U-16 } & \multicolumn{3}{|c|}{ U-19 } & \multicolumn{3}{|c|}{ National } & \multicolumn{3}{|c|}{ International } \\
\hline & n & Mean & $\%$ & n & Mean & $\%$ & $\mathbf{n}$ & Mean & $\%$ & n & Mean & $\%$ & n & Mean & $\%$ \\
\hline $\begin{array}{l}\text { Non-con- } \\
\text { tacted dig }\end{array}$ & 344 & 2.87 & $18.42^{\mathrm{A}}$ & 389 & 3.24 & $20.68^{\mathrm{A}}$ & 362 & 3.02 & $22.01^{\mathrm{A}}$ & 500 & 4.17 & $34.19^{\uparrow^{*} \downarrow \mathrm{A}}$ & 544 & 4.61 & $38.73^{\uparrow^{*} \downarrow \mathrm{A}}$ \\
\hline $1^{\text {st }}$ tempo & 19 & 0.16 & 5.72 & 54 & 0.45 & $13.35^{\uparrow}$ & 94 & 0.78 & $25.67^{\uparrow *}$ & 182 & 1.52 & $37.74^{\uparrow^{*} \downarrow}$ & 175 & 1.48 & $31.39^{\uparrow^{*}}$ \\
\hline $2^{\text {nd }}$ tempo & 0 & 0.00 & $0.00^{\mathrm{a}}$ & $14 w$ & 0.12 & $3.96^{\dagger a}$ & 31 & 0.26 & $6.91^{\uparrow a}$ & 221 & 1.84 & $43.64^{\uparrow * \downarrow}$ & 306 & 2.59 & $57.28^{\uparrow * \downarrow \downarrow a}$ \\
\hline $3^{\text {rd }}$ tempo & 325 & 2.71 & $94.28^{\mathrm{ab}}$ & 321 & 2.68 & $82.69^{\uparrow a b}$ & 237 & 1.98 & $67.42^{\uparrow^{* a b}}$ & 97 & 0.81 & $18.61^{\uparrow^{*} \downarrow a b}$ & 63 & 0.53 & $11.32^{\uparrow^{*} \downarrow \backslash \mathrm{ab}}$ \\
\hline $\begin{array}{l}\text { Contacted } \\
\text { digs }\end{array}$ & 1592 & 13.27 & 81.58 & 1481 & 12.34 & 79.32 & 1256 & 10.47 & 77.99 & 998 & 8.32 & $65.81^{\uparrow^{*} \downarrow}$ & 855 & 7.25 & $61.27^{\uparrow^{*} \downarrow}$ \\
\hline $1^{\text {st }}$ tempo & 114 & 0.95 & 6.80 & 115 & 0.96 & 7.68 & 258 & 2.15 & $20.81^{\uparrow^{*}}$ & 218 & 1.82 & $22.21^{{ }^{*}}$ & 172 & 1.46 & $20.19^{{ }^{*}}$ \\
\hline $2^{\text {nd }}$ tempo & 0 & 0.00 & $0.00^{\mathrm{a}}$ & 38 & 0.32 & $2.33^{\uparrow a}$ & 72 & 0.60 & $6.28^{\uparrow a}$ & 444 & 3.70 & $44.67^{\uparrow * \downarrow a}$ & 448 & 3.80 & $51.44^{\uparrow^{*} \downarrow \backslash a}$ \\
\hline $3^{\text {rd }}$ tempo & 1478 & 12.32 & $93.20^{\mathrm{ab}}$ & 1328 & 11.07 & $89.99^{\mathrm{ab}}$ & 926 & 7.72 & $72.90^{\uparrow^{* a} \mathrm{ab}}$ & 336 & 2.80 & $33.13^{\uparrow^{*} \downarrow \mathrm{ab}}$ & 235 & 1.99 & $28.37^{\uparrow^{*} \mathrm{aab}}$ \\
\hline Total & 1936 & 16.13 & 100 & 1870 & 15.58 & 100 & 1618 & 13.48 & 100 & 1498 & 12.48 & 100 & 1399 & 11.86 & 100 \\
\hline
\end{tabular}

Note. ${ }^{\uparrow} p<.01$ when compared to U-14. ${ }^{*} p<.01$ when compared to U-16. ${ }^{\downarrow} p<.01$ when compared to U-19. $p<.01$ when compared to national category. ${ }^{\text {A }}$ Significant differences when compared to "Contacted digs". " Significant differences when compared to " 1 st tempo dig". ${ }^{\text {b }}$ Significant differences when compared to " $2^{\text {nd }}$ tempo dig".

When analysing first tempo digs (Table 7), predominance of positive digs in U-14, U-16, and U-19 and of dig errors in the senior national and international categories were observed. An increase in errors beginning at U-19 and a statistically significant decrease in negative and positive digs starting at the national senior category were found. Concerning second tempo digs (Table 7), there was a predominance of dig errors in all categories, except for U-14 as no data were recorded. There were no differences between categories for the evolution of performance of this action, yet a decrease in negative digs and an increase in positive digs 
were observed. Regarding the analysis of third tempo digs (Table 7), a predominance of positive digs in all categories was observed. There was a significant decrease in dig errors (between the U-14 and international senior categories) as well as in negative digs (starting with the U-19 category). On the other hand, an increase in positive digs beginning with the U-16 category was observed.

When analysing the statistical data of the total number of digs and first tempo digs (Table 8), there was a significant increase in the percentage of error and in the positive-dig-to-negative-dig ratio as well as a significant decrease in the coefficient, efficiency, and effectiveness. All these changes were significant starting at the national senior level, except for the first tempo defence ratio variable, which showed a significant increase in the beginning at the U-19 category. For the second tempo dig, a significant increase in the positive-dig-to-negative-dig ratio between the national category and U-16 was observed. For the third tempo defence, there were an increase in the coefficient, efficiency (starting at U-19), and efficiency (starting with the national category) and decrease in the percentage of errors (for the international senior category) and in the ratio (starting at the national category).

Table 7. Performance of contacted digs with regard to spike tempo, and statistically significant differences between categories.

\begin{tabular}{|c|c|c|c|c|c|c|c|c|c|c|c|c|c|c|c|c|}
\hline & & \multicolumn{3}{|c|}{ U-14 } & \multicolumn{3}{|c|}{ U-16 } & \multicolumn{3}{|c|}{ U-19 } & \multicolumn{3}{|c|}{ National } & \multicolumn{3}{|c|}{ International } \\
\hline & & n & Mean & $\%$ & n & Mean & $\%$ & $\mathbf{n}$ & Mean & $\%$ & $\mathbf{n}$ & Mean & $\%$ & n & Mean & $\%$ \\
\hline \multirow{3}{*}{$\begin{array}{c}1^{\text {st }} \text { tempo } \\
\text { dig }\end{array}$} & Error & 22 & 0.18 & 17.63 & 29 & 0.24 & 21.64 & 79 & 0.66 & $30.48^{\uparrow}$ & 118 & 0.98 & $55.15^{\uparrow * \downarrow}$ & 89 & 0.75 & $53.83^{\uparrow^{*} \downarrow}$ \\
\hline & Negative dig & 29 & 0.24 & 25.72 & 27 & 0.23 & 23.23 & 63 & 0.53 & 23.55 & 32 & 0.27 & $13.72^{\downarrow a}$ & 15 & 0.13 & $7.87^{\uparrow^{*} \downarrow a}$ \\
\hline & Positive dig & 63 & 0.53 & $56.64^{\mathrm{ab}}$ & 59 & 0.49 & $55.13^{\mathrm{ab}}$ & 116 & 0.97 & $45.98^{\mathrm{b}}$ & 68 & 0.57 & $31.13^{\uparrow^{*} \downarrow \mathrm{ab}}$ & 68 & 0.58 & $38.30^{\uparrow \mathrm{b}}$ \\
\hline Tota & & 114 & 0.95 & 100 & 115 & 0.96 & 100 & 258 & 2.15 & 100 & 218 & 1.82 & 100 & 172 & 1.46 & 100 \\
\hline \multirow{3}{*}{$\begin{array}{c}2^{\text {nd }} \text { tempo } \\
\text { dig }\end{array}$} & Error & 0 & 0.00 & - & 14 & 0.12 & 40.08 & 37 & 0.31 & 54.97 & 227 & 1.89 & 52.66 & 222 & 1.88 & 48.47 \\
\hline & Negative dig & 0 & 0.00 & - & 13 & 0.11 & 36.31 & 13 & 0.11 & 21.78 & 70 & 0.58 & $14.31^{\mathrm{a}}$ & 58 & 0.49 & $13.87^{\mathrm{a}}$ \\
\hline & Positive dig & 0 & 0.00 & - & 11 & 0.09 & 23.61 & 22 & 0.18 & 23.25 & 147 & 1.23 & $33.03^{\mathrm{ab}}$ & 168 & 1.42 & $37.65^{\mathrm{b}}$ \\
\hline Total & & 0 & 0.00 & - & 38 & 0.32 & 100 & 72 & 0.60 & 100 & 444 & 3.70 & 100 & 448 & 3.80 & 100 \\
\hline \multirow{3}{*}{$\begin{array}{c}3^{\text {rd }} \text { tempo } \\
\quad \text { dig }\end{array}$} & Error & 405 & 3.38 & 30.11 & 351 & 2.93 & 25.77 & 238 & 1.98 & 27.26 & 89 & 0.74 & 28.39 & 52 & 0.44 & $25.60^{\uparrow}$ \\
\hline & Negative dig & 408 & 3.40 & 26.58 & 329 & 2.74 & 24.60 & 203 & 1.69 & $20.29^{\uparrow a}$ & 47 & 0.39 & $13.31^{\uparrow^{*} \downarrow a}$ & 20 & 0.17 & $7.81^{\uparrow^{*} \downarrow \mathrm{a}}$ \\
\hline & Positive dig & 665 & 5.54 & $43.31^{\mathrm{ab}}$ & 648 & 5.40 & $49.63^{\uparrow a b}$ & 485 & 4.04 & $52.45^{\text {†ab }}$ & 200 & 1.67 & $58.29^{\uparrow a b}$ & 163 & 1.38 & $66.59^{\uparrow * \downarrow a b}$ \\
\hline Total & & 1478 & 12.32 & 100 & 1328 & 11.07 & 100 & 926 & 7.72 & 100 & 336 & 2.80 & 100 & 235 & 1.99 & 100 \\
\hline
\end{tabular}

Note. ${ }^{\dagger} p<.01$ when compared to U-14. ${ }^{*} p<.01$ when compared to U-16. ${ }^{\downarrow} p<.01$ when compared to U-19. ${ }^{\downarrow} p<.01$ when compared to national category. a

Significant differences when compared to "error". ' Significant differences when compared to "negative dig".

Table 8. Dig performance values and statistically significant differences among categories

\begin{tabular}{|c|c|c|c|c|c|c|c|c|c|c|c|}
\hline \multirow{2}{*}{$\begin{array}{c}\text { Types of court } \\
\text { defence }\end{array}$} & \multirow[t]{2}{*}{ Statistical data } & \multicolumn{2}{|c|}{ U-14 } & \multicolumn{2}{|c|}{ U-16 } & \multicolumn{2}{|c|}{ U-19 } & \multicolumn{2}{|c|}{ National } & \multicolumn{2}{|c|}{ International } \\
\hline & & Mean & SD & Mean & SD & Mean & SD & Mean & SD & Mean & SD \\
\hline \multirow{5}{*}{ Total dig } & Coefficient & 1.59 & 0.51 & 1.72 & 0.48 & 1.69 & 0.52 & $1.37^{\uparrow^{*} \downarrow}$ & 0.55 & $1.50^{*}$ & 0.62 \\
\hline & Efficacy (\%) & 44.33 & 17.80 & 48.90 & 17.82 & 49.31 & 19.18 & $41.24^{*} \downarrow$ & 19.06 & 46.55 & 21.65 \\
\hline & Error $(\%)$ & 29.31 & 18.52 & 26.33 & 15.35 & 29.93 & 17.22 & $45.40^{\uparrow^{*} \downarrow}$ & 19.86 & $42.74^{\uparrow^{*} \downarrow}$ & 20.88 \\
\hline & Efficiency (\%) & 15.07 & 33.73 & 22.57 & 30.52 & 19.29 & 33.84 & $-4.11^{\uparrow * \downarrow}$ & 36.62 & $3.78^{* \downarrow}$ & 40.56 \\
\hline & Positive:error ratio & $1: 0.59$ & 0.76 & $1: 0.55$ & 0.84 & $1: 0.57$ & 1.03 & $1: 1.05^{{ }^{*} \downarrow}$ & 1.23 & $1: 0.91^{\uparrow * \downarrow}$ & 1.22 \\
\hline \multirow{5}{*}{$1^{\text {st }}$ tempo dig } & Coefficient & 1.96 & 1.06 & 1.89 & 1.16 & 1.61 & 1.03 & $1.07^{* * \downarrow}$ & 1.08 & $1.23^{\uparrow^{*}}$ & 1.17 \\
\hline & Efficacy (\%) & 56.65 & 43.30 & 55.12 & 45.15 & 45.98 & 38.95 & $31.11^{\uparrow * \downarrow}$ & 36.87 & $38.29^{\uparrow}$ & 39.88 \\
\hline & Error $(\%)$ & 17.62 & 31.68 & 21.65 & 37.30 & $30.43^{\uparrow}$ & 35.22 & $55.17^{\uparrow^{*} \downarrow}$ & 40.94 & $53.84^{{ }^{*} \downarrow}$ & 41.86 \\
\hline & Efficiency (\%) & 39.01 & 65.48 & 33.50 & 73.40 & 15.49 & 66.35 & $-24.01^{{ }^{*} \downarrow}$ & 72.89 & $-15.53^{\uparrow * \downarrow}$ & 78.42 \\
\hline & Positive:error ratio & $1: 0.35$ & 0.45 & $1: 0.49$ & 0.61 & $1: 0.68^{\uparrow^{*}}$ & 0.55 & $1: 1.74^{\uparrow^{*}}$ & 1.01 & $1: 1.31^{\uparrow^{*}}$ & 0.86 \\
\hline \multirow{5}{*}{$2^{\text {nd }}$ tempo dig } & Coefficient & . & . & 1.07 & 1.02 & 0.92 & 0.95 & 1.13 & 0.79 & 1.27 & 0.89 \\
\hline & Efficacy (\%) & . & . & 23.62 & 37.65 & 23.23 & 31.96 & 33.03 & 27.86 & 37.65 & 31.30 \\
\hline & Error $(\%)$ & . & . & 40.05 & 42.79 & 54.97 & 43.29 & 52.67 & 29.23 & 48.48 & 30.61 \\
\hline & Efficiency (\%) & . & . & -16.43 & 68.69 & -31.73 & 66.45 & -19.64 & 52.98 & -10.83 & 58.67 \\
\hline & Positive:error ratio & . & . & $1: 1.27$ & 0.47 & $1: 1.68$ & 1.61 & $1: 1.54^{*}$ & 1.27 & $1: 1.32$ & 0.92 \\
\hline \multirow{5}{*}{$3^{\text {rd }}$ tempo dig } & Coefficient & 1.57 & 0.53 & 1.74 & 0.47 & $1.78^{\uparrow}$ & 0.61 & $1.88^{\uparrow}$ & 0.98 & $2.08^{\uparrow^{*} \downarrow}$ & 1.03 \\
\hline & Efficacy $(\%)$ & 43.35 & 18.67 & 49.65 & 18.19 & $52.48^{\uparrow}$ & 22.46 & $58.30^{\uparrow}$ & 35.26 & $66.61^{{ }^{*} \downarrow}$ & 36.02 \\
\hline & Error (\%) & 30.12 & 19.18 & 25.81 & 15.57 & 27.29 & 20.12 & 28.40 & 32.43 & $25.57^{\uparrow}$ & 34.44 \\
\hline & Efficiency (\%) & 13.19 & 35.17 & 23.88 & 29.97 & 25.16 & 39.44 & $29.94^{\uparrow}$ & 63.86 & $40.97^{\uparrow^{*} \downarrow}$ & 67.65 \\
\hline & Positive:error ratio & $1: 0.61$ & 0.99 & $1: 0.54$ & 0.79 & 1:0.49 & 0.88 & $1: 0.45^{\uparrow^{*} \downarrow}$ & 0.54 & $1: 0.32^{\uparrow^{*} \downarrow}$ & 0.45 \\
\hline
\end{tabular}

Note. ${ }^{\uparrow} p<.01$ when compared to U-14. ${ }^{*} p<.01$ when compared to U-16. ${ }^{\downarrow} p<.01$ when compared to U-19. $p<.01$ when compared to national category. 


\section{Discussion}

This study demonstrates the technical-tactical performance profile of blocking and court defence depending on attack tempo at various age groups and categories of competition in men's volleyball. As the category increases, there is a significant increase in block and court defence for first and second tempo spikes and a significant decrease in these actions for third tempo spikes, with or without contact with the ball. Regarding performance, only the block and court defence for third tempo spikes showed increased efficiency (block points and digs which allow a team to set up their counterattack).

An increase in contacted blocks when progressing to higher categories may be related to players' anthropometric development and physical abilities (Grgantov et al., 2006). Physical improvements would restrain the spike; thus increasing the percentage of contacted blocks. However, players' development may not be enough to prevent a decline in the percentage of contacted digs which occur when the ball avoids a block and heads toward the opponent's court. When comparing blocks and digs, the percentage of ball contacts for digs is greater than the percentage of ball contacts for blocks throughout all categories. This could be related to a shortage of time to set up a block depending on how close one is to the opponent's spike. Thus, the proximity of blockers to the spike would hinder their perception and interception of the ball and its path, while defenders would have more time to identify and respond to it (Selinger \& Ackerman-Blount, 1985).

An increase in blocks and digs for first and second tempo spikes (contacted and non-contacted) demonstrates that the higher the category, the higher the speed of play. This is positively affected by an improvement in reception and court defense performance which occurs in higher ages and categories of competition (García-Alcaraz, Palao, \& Ortega, 2014; Grgantov et al., 2006). An increase in the speed of the game may reduce the time available for defensive actions, thus limiting both the number of players who may block (Afonso, Mesquita, \& Palao, 2005) and the defensive moves (Afonso et al., 2005, 2010; Selinger \& Ackermann-Blount, 1985). This limitation of perception and execution on defensive actions is intended to counteract the increase in the height of the net (FIVB, 2008), the increase in the height of the players, and the development of players' physical abilities (e.g. jump, speed, etc.) (Grgantov et $a l ., 2006)$, which are variables that may favour the performance of defensive actions when progressing to higher categories.

Regarding the performance of the block and court defence, there was a significant improvement in performance for slow attacks when analysing higher categories. This may be related to the amount of time available for defenders to execute their defensive actions. Previous studies have demonstrated that a shortage in time determines players' defensive moves (Afonso et al., 2010; Afonso et al., 2005; Selinger \& Ackermann-Blount, 1985), thus limiting the execution of a cohesive block (Bergeles \& Nikolaidou, 2011) and the number of blockers (Afonso et al., 2005). On the other hand, an increase in time for slow attacks fosters anticipation, decision-making, and players' moves when blocking and defending. This is because slow attack times are related to low-performance receptions (Papadimitriou, Paschali,
Sermaki, Mellas, \& Papas, 2004), which limit the options for attacking and determine the setting zone, thus promoting the set-up of a block with a larger number of players (Afonso et al., 2005). An improvement in performance of court defence in slow attacks may also be due to the relationship between court defence (i.e. the second line of defence) and the block (i.e. the first line of defence). Increasing the number of blockers (Afonso et al., 2005), or setting up a more cohesive block (Bergeles \& Nikolaidou, 2011), reduces the number of trajectories of attack aimed at areas not covered by defenders, thus facilitating the performance of court defence.

The significant improvement in performance of blocks and court defence for slow attacks may explain the significant decrease in the percentage of blocks and digs contacted in slow attacks. Regarding the block, this decline would be related to the spiker's performance, particularly in one's ability to avoid getting blocked. Thus, the increase in training and players' experience as they progress to higher categories would improve their ability to spike. In contrast, temporal limitations of the block in fast attacks would be an advantage for spikers, who may perform better when attacking against this limited block. In this regard, Rocha and Barbanti (2004) found an increase in the attack's efficacy when the ball contacts the block, although the attack tempo is not specified. As for defence, a significant increase in the percentage of contacted digs in fast attacks (first and second tempo) may be related to a decrease in the number of blockers (Afonso et al., 2005), which promotes the increase in the number of balls headed toward diggers.

These results present the performance profile of blocking and court defence according to attack tempo in various categories of competition. The data provide reference values which may be useful when setting training and competition objectives for the various categories. Due to the relationship between defensive actions and attack tempo and between attack tempo and performance in previous actions (i.e. reception/defence and set) (Eom $\&$ Schutz, 1992), there is a need for further research on the effect of these variables on block and court defence performance. Thus, the attack that is set up upon receiving the ball is different in terms of offensive actions that are set up from a team's defence, mainly due to the setter's location and the spikers' availability to counterattack as quickly as possible (Castro \& Mesquita, 2010). Variables such as spike direction distance between the point where the spiker hits the ball and the blocker positions his hands, ball speed, number of blockers, defence area, player role, set momentum, etc., may also need further analysis.

\section{Conclusions}

The results of this study show changes in the performance of the block and court defence depending on various age groups and competition level. When progressing to higher categories, there is a significant increase in the percentage of contacted blocks and digs with no ball contact, a significant increase in the percentage of defensive actions (i.e. blocks and digs) contacted in quick attacks (i.e. second and first tempo), and a significant improvement in performance in slow attacks (i.e. third tempo). These data may contribute to developing a technical-tactical performance profile of blocking and court defence in various 
categories of competition. These values may help to develop training programs, assess performance in competition, and expand knowledge about variables that describe performance. Nevertheless, the complex interaction of defensive actions with other game variables, such as attack time, attack zone, height of block, etc., requires further study which would fulfil a gap in current knowledge of performance variables.

\section{References}

Afonso, J., \& Mesquita, I. (2011). Determinants of block cohesiveness and attack efficacy in high-level women's volleyball. European Journal of Sport Science, 11(1), 69-75.

Afonso, J., Mesquita, I., \& Palao, J.M. (2005). Relationship between the tempo and zone of spike and the number of blockers against the hitters. International Journal of Volleyball Research, 8(1), 19-23.

Afonso, J., Mesquita, I., Marcelino, R., \& Da Silva, J.A. (2010). Analysis of the setter's tactical action in high-performance women's volleyball. Kinesiology, 42, 82-89.

Anguera, M.T. (2003). Diseños observacionales en la actividad física y el deporte: estructura, alcance y nuevas perspectivas. In A. Oña, \& A. Bilbao (Eds.), II Congreso Mundial de Ciencias de la Actividad Física y el Deporte: Deporte y Calidad de vida (pp. 253-282). Granada (Spain): Gráficas Alhambra.

Bergeles, N., \& Nikolaidou, M E. (2011). Setter's performance and attack tempo as determinants of attack efficacy in Olympic-level male volleyball teams. International Journal of Performance Analysis in Sport, 11(3), 535-544.

Castro, J.M., \& Mesquita, I. (2010). Analysis of the attack tempo determinants in volleyball's complex II: A study on elite male teams. International Journal of Performance Analysis in Sport, 10(3), 197-206.

Castro, J.M., Souza, A., \& Mesquita, I. (2011). Attack efficacy in volleyball: Elite male teams. Perceptual and Motor Skills, 113(2), 395-408.

Costa, G., Caetano, J., Neiva, N., Junqueira, G., Afonso, J., Costa, P., \& Mesquita, I. (2011). Determinants of attack tactics in youth male elite volleyball. International Journal of Performance Analysis in Sport, 11(1), 96-104.

Eom, H. J., \& Schutz, R.W. (1992). Statistical analyses of volleyball team performance. Research Quarterly for Exercise and Sport, 63(1), 11-18.

FIVB (2008). Reglas oficiales del voleibol [Official volleyball rules]. Retrieved from www.rfevb.com.

García-Alcaraz, A., Palao, J.M., \& Ortega, E. (2014). Perfil de rendimiento técnico-táctico de la recepción en función de la categoría de competición en voleibol masculino. Kronos, 13(1). Retrieved from http://g-se.com/es/journals/kronos/articulos/perfil-de-rendimiento-tecnico-tactico-de-la-recepcion-en-funcion-de-la-categoria-de-competicion-en-voleibol-masculino-1706

Grgantov, Z., Katic, R., \& Jankovic, V. (2006). Morphological characteristics, technical and situation efficacy of young female volleyball players. Collegium Antropologicum, 1, 87-96.

Hughes, M.D., \& Daniel, R. (2003). Playing patterns of elite and nonelite volleyball. International Journal of Performance Analysis in Sport, 3(1), 50-56.
Malina, R.M., \& Bouchard, C. (1991). Growth, maturation, and physical activity. Champaign, IL: Human Kinetics.

Palao, J. M., Santos, J.A., \& Ureña, A. (2007). Effect of the manner of spike execution on spike performance in volleyball. International Journal of Performance Analysis in Sport, 7(2), 126-138.

Papadimitriou, K., Paschali, E., Sermaki, I., Mellas, S., \& Papas, M. (2004). The effect of the opponents' serve on the offensive actions of Greek setters in volleyball games. International Journal of Performance Analysis in Sport, 4(1), 23-33.

Rocha, C., \& Barbanti, V.J. (2004). Analysis of factors that influence the attack in high level male volleyball. Brazilian Journal of Physical Education and Sport, 18(4), 103-114.

Selinger, A., \& Ackermann-Blount, J. (1985). Arie Selinger's power volleyball. New York: St. Martin Press.

Stamm, R., Stamm, M., \& Thomson, K. (2005). Role of adolescent female volleyball players' psychophysiological properties and body build in performance of different elements of the game. Perceptual and Motor Skills, 101, 108-120.

Stanganelli, L.C.R., Dourado, A.C., Oncken, P., Mançan, S., \& Costa, S.C. (2008). Adaptations on jump capacity in Brazilian volleyball players prior to the under-19 world championship. Journal of Strength and Conditioning Research, 22(3), 741-749.

Stone, J. (2002). Digging and ball control. In D. Shondell, \& C. Reynaud (Eds.), The volleyball coaching bible (pp. 163-176). Champaign, IL: Human Kinetics.

\section{Author's note}

Antonio García-de-Alcaraz is affiliated with the Department of Sports, Faculty of Physical Activity and Sport Sciences, Polytechnic University of Madrid, Spain.

Enrique Ortega is affiliated with the Department of Physical Activity and Sport, Faculty of Sport Sciences, University of Murcia, Spain.

José M. Palao is affiliated with Department of Health, Exercise Science and Sport Management. University of Wisconsin, Parkside, United States.

\section{Corresponding author}

Antonio García de Alcaraz Serrano

Facultad de Ciencias de la Actividad Física y del Deporte, INEF. Departamento de Deportes. C/ Martín Fierro, 7, Spain.

Email: antoniogadealse@gmail.com

Manuscript received on November 10, 2014

Manuscript accepted on February 10, 2016

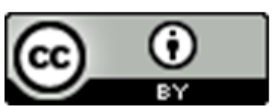

Motriz. The Journal of Physical Education. UNESP. Rio Claro, SP, Brazil - eISSN: 1980-6574 - under a license Creative Commons - Version 3.0 